\title{
Prevalence of Metabolic Syndrome in Obese Children and Adolescents using Three Different Criteria and Evaluation of Risk Factors
}

\author{
Özlem Sangun ${ }^{1}$, Bumin Dündar ${ }^{1}$, Muhammet Köşker ${ }^{1}$, Özgür Pirgon², Nihal Dündar ${ }^{3}$, \\ ${ }^{1}$ Department of Pediatrics, Division of Pediatric Endocrinology, Faculty of Medicine, Suleyman Demirel University, Isparta, Turkey \\ ${ }^{2}$ Department of Pediatrics, Division of Pediatric Endocrinology, Research and Training Hospital, Konya, Turkey \\ ${ }^{3}$ Department of Pediatrics, Faculty of Medicine, Suleyman Demirel University, Isparta, Turkey
}

\begin{abstract}
Objective: To compare the prevalence of the metabolic syndrome (MS) in Turkish obese children and adolescents by using three different definitions and to assess the risk factors through a retrospective evaluation of anthropometric and laboratory parameters.

Methods: Sixty hundred and fourteen obese patients (307 male, 307 female; mean age: $11.3 \pm 2.5$ years) were included in the study. Medical history, physical examination, anthropometric measurements, results of biochemical and hormonal assays were obtained from the hospital records. MS was diagnosed according to the modified World Health Organization (WHO), Cook and the International Diabetes Federation (IDF) consensus criteria.

Results: The prevalence of MS was found to be 39\%, 34\% and 33\% according to the modified WHO, Cook and the IDF consensus criteria, respectively. MS prevalence in patients aged 12-18 years was significantly higher than that in patients between 7 and 11 years of age $(p<0.05)$. Pubertal patients had a significantly higher MS prevalence than the non-pubertal cases $(p<0.05)$. MS prevalence was also significantly higher in children who had a family history of heart disease, diabetes, obesity and hypertension as well as in those who had not been breast-fed $(p<0.05)$.

Conclusion: The use of the modified WHO criteria was found to result in a slightly higher prevalence rate for MS as compared to the other criteria. The prevalence of MS in our study population was higher than that reported in most previous studies in Turkey. A positive family history, puberty and not being breastfed in infancy were shown to be significant risk factors for MS in childhood.

Key words: Childhood metabolic syndrome, prevalence, risk factors, breastfed, puberty
\end{abstract}

Conflict of interest: None declared

Received: 30.12 .2010

Accepted: 01.04.2011

\section{Introduction}

Obesity in children and adolescence is on the increase due to changes in lifestyle and nutrition behaviors (1). Children who used to play outdoors in the past years are today more likely to spend their time in front of television and computer screens. It is known that $1 / 3$ of obese children and $80 \%$ of obese adolescents remain obese when they reach adulthood (2). The World Health Organization (WHO) defines obesity as "abnormal or excessive fat accumulation that presents a risk to health" (3). Obese children are also more prone to have metabolic syndrome (MS), type 2 diabetes, hypertension, hyperlipidemia, cardiovascular disease and some types of cancer (colon, breast, gallbladder, endometrium) (4).

A set of risk factors associated with obesity and insulin resistance lead to chronic changes in various tissues and organs. There are racial differences in the prevalence of obesity and in the prevalence of obesity-related health complications. Although it is known that accurate management of $\mathrm{MS}$ is fundamental in controlling the current global epidemics of cardiovascular disease and diabetes mellitus, the predisposing risk factors or epidemiologic characteristics of MS are not yet clearly defined in children and adolescents (5).

The prevalence of MS in different countries has been reported to be $3-4 \%$ (6). Reports from different provinces in

Address for Correspondence

Bumin Dündar MD, Suleyman Demirel University, Faculty of Medicine, Department of Pediatric Endocrinology, 32260, Cunur, Isparta, Turkey Phone: +90 2462119311 E-mail: bumindundar@gmail.com

(c) Journal of Clinical Research in Pediatric Endocrinology, Published by Galenos Publishing. 
Turkey indicate that the prevalence of MS ranges around $3 \%$, while it may be as high as $20-38 \%$ in obese children $(7,8,9,10)$. In a recent study, the MS prevalence based on the International Diabetes Federation (IDF) guidelines was reported to be $2.3 \%$ in the total population. The prevalence was found to be similar by both IDF and National Cholesterol Education Program (NCEP) definitions, but it was higher when assessed according to the WHO definition (11).

Although there is an increasing number of reports regarding childhood MS, there is still no universal agreement on which level, and even which criteria, should be used for the diagnosis of MS. The most commonly applied criteria recommended for use in comparative studies are the modified WHO, Cook and the IDF consensus criteria $(12,13)$. The aim of this study was to determine the prevalence of and risk factors for MS in obese children and to compare the three definition criteria for the diagnosis of MS in children and adolescents.

\section{Methods}

Sixty hundred and thirty-five obese children and adolescents aged between 7 and 18 years were recruited from obese children who presented to the Pediatric Endocrinology Unit. The children were required to meet the following inclusion criteria: (1) age, 7-18 years; (2) a BMI greater than the 95th percentile for age and gender based on the standards of the Centers for Disease Control and Prevention (CDC); (3) absence of a prior major illness, including type 1 or 2 diabetes. Being on medications or having a condition known to influence body composition, insulin action or insulin secretion (e.g. glucocorticoid therapy, hypothyroidism and Cushing's disease) was a reason for exclusion. Twenty-one cases were excluded due to inadequacy of the information in their files. Thus, 614 obese children (307 girls and 307 boys) were included in the study.

The mean age of the group was $11.3 \pm 2.5$ years (range: 7-18 years) and the mean body mass index standard deviation score (BMI-SDS) was 2.57 \pm 0.59 . Data on age, gender, birth weight, and feeding in the first 6 months (regarding exclusive breast-feeding) were obtained from the medical records. Cardiovascular disease, type 2 diabetes, obesity and hypertension in the family (first and second degree relatives) were also recorded from the specifically asked questions in the patient reports.

Height and weight were measured by the same pediatrician. Height was measured to the nearest $0.5 \mathrm{~cm}$ on a standard height board, and weight was determined to the nearest $0.1 \mathrm{~kg}$ on a standard physician's beam scale with the subject dressed only in light underwear and no shoes. $\mathrm{BMI}$ was calculated as weight in kilograms divided by height in meters squared. All measuring devices were weekly calibrated. Weight SDS, height SDS, BMI, and BMI-SDS were calculated for all patients. The degree of obesity was quantified using the Cole's least mean square method, which normalizes the BMI skewed distribution and expresses BMI as an SDS (BMI-SDS). This measure gives age- and sex-specific estimates of the distribution median, the coefficient of variation and the degree of skewness by a maximum-likelihood fitting technique. Obesity was defined as a BMI-SDS $\geq 1.64$. Percentile and SDS assessments of weight, height and BMI were made according to the standards of the CDC (14). Waist circumference was measured at the level of the umbilicus with the patient standing and breathing normally. Pubertal maturation was evaluated according to Tanner stages (15). Blood pressure was measured with the auscultatory method using appropriate cuff, in the fasting state and after 20 minutes of rest. Values over 90th percentile according to the age, sex and height tables were considered high (16).

\section{Biochemical Definitions and Insulin Sensitivity Check Indices}

Plasma glucose, insulin and lipid levels were measured in blood samples obtained in the morning by venipuncture after an overnight fast. Thyroid, liver and kidney functions were also assessed. In patients who were found to have a fasting blood glucose (FBG) level of $>100 \mathrm{mg} / \mathrm{dL}$, an oral glucose tolerance test (OGTT) was conducted in the morning, after an overnight fast, using a dose of $1.75 \mathrm{~g}$ glucose/kg body weight (to a maximum of $75 \mathrm{~g}$ ) Venous blood samples were obtained at 0, 30, 60, 90 and 120 minute to measure plasma glucose and insulin levels. After clotting, the serum was separated and immediately subjected to analysis. The patients were defined as having "impaired glucose tolerance" or "diabetes", if the glucose level was between $140-200 \mathrm{mg} / \mathrm{dL}$ or $>200 \mathrm{mg} / \mathrm{dL}$, respectively, in the $2^{\text {nd }}$ hour of the OGTT.

Hyperinsulinism was defined according to the pubertal stage: prepubertal $>15 \mathrm{mU} / \mathrm{L}$; midpuberty (stages 2-4) >30 $\mathrm{mU} / \mathrm{L}$ (17). Homeostasis model assessment-insulin resistance (HOMA-IR) was calculated according to the formula proposed by Levy et al (18):

HOMA-IR=Fasting insulin $(\mathrm{mUl} / \mathrm{mL}) \times$ fasting glucose (mmol/L)/22.5

Plasma concentrations of total cholesterol, high-density lipoprotein-cholesterol (HDL-cholesterol), low-density lipoprotein-cholesterol (LDL-cholesterol), triglycerides and blood glucose were measured using routine enzymatic methods. Fasting HDL-cholesterol and LDL-cholesterol levels were evaluated based on the modified definition criteria of the WHO, Cook and the IDF consensus, and were defined as high, normal or low according to age and sex percentiles $(12,13,19)$. HbA1c was measured by boronic acid affinity chromatography method. 


\section{Definitions of Metabolic Syndrome}

MS was defined based on the modified WHO criteria adapted for children. The subjects were diagnosed as having MS if they met 3 of the following 4 WHO criteria (19): (1) obesity (BMI $>95^{\text {th }}$ percentile for age and sex); (2) abnormal glucose homoeostasis (fasting hyperinsulinemia, impaired fasting glucose, or impaired glucose tolerance); (3) hypertension (systolic blood pressure $>95^{\text {th }}$ percentile for age, sex and height); and (4) dyslipidaemia [high triglycerides ( $>105 \mathrm{mg} / \mathrm{dL}$ in children $<10$ years of age and $>136 \mathrm{mg} / \mathrm{dL}$ in children $\geq 10$ years of age), low HDLcholesterol $(<35 \mathrm{mg} / \mathrm{dL})$ or high total cholesterol (>95th percentile)].

The risk factors were evaluated according to the modified WHO criteria.

The patients were also assessed with the modified Cook criteria (12) and diagnosed as MS if they met at least three of the conditions listed below: (1) triglyceride level >110 mg/dL; (2) HDL-cholesterol level <40 mg/dL; (3) fasting blood glucose $>110 \mathrm{mg} / \mathrm{dL}$; (4) waist circumference $>90^{\text {th }}$ percentile for age and sex [normal values for Turkish children (20) were used to assess waist circumference]; and (5) systolic and diastolic blood pressures $>90^{\text {th }}$ percentile according to age, sex and height.

The IDF definition of MS for children aged 10 years or older includes $\mathrm{BMI}>90^{\text {th }}$ percentile for age and sex and presence of two or more of the following findings: (1) triglycerides > $150 \mathrm{mg} / \mathrm{dL}$; (2) HDL-cholesterol < $40 \mathrm{mg} / \mathrm{dL}$; (3) systolic blood pressure $>130 \mathrm{mmHg}$, diastolic $>85$ $\mathrm{mmHg}$; and (4) plasma glucose $>5.6 \mathrm{mmol} / \mathrm{L}$ or $>100 \mathrm{mg} / \mathrm{dL}$ or known type 2 diabetes (13).

\section{Statistical Analysis}

Statistical analyses were performed by SPSS (Statistical Package for Social Sciences) for Windows 15.0 (SPSS Inc., Chicago, IL) program. The data were presented as mean \pm standard deviation (SD) values. Chi-square test and student's t-test were used to compare the ratios and the means of the groups, respectively. A p-value of less than 0.05 was considered statistically significant.

\section{Results}

According to the modified WHO criteria, 240 of the 614 patients $(39 \%)$ were diagnosed with MS. The subjects were between 7 and 18 years of age and after reevaluation with the modified Cook criteria, MS was detected in 209 of them (34\%). There were 408 patients aged between 10 and 16 years, of whom 127 (31\%) had MS according to the IDF-2007 criteria for children and adolescents. The subjects with a WC $>90^{\text {th }}$ percentile constituted $38 \%$ of the cases who were below 10 years of age $(n=76 / 198)$. The overall prevalence of $\mathrm{MS}$ in our population according to the IDF criteria was $33 \%$.
The clinical and metabolic characteristics of the patients are listed in Table 1. BMI-SDS values in the obese males were significantly higher than those in the females and, males were predominant among MS patients $(p<0.001)$. Although all $\mathrm{HbA} 1 \mathrm{c}$ levels were within the normal reference range, males had significantly higher $\mathrm{HbA} 1 \mathrm{c}$ levels than females $(p=0.006)$.

Mean age, BMI-SDS and weight to height $(\mathrm{W} / \mathrm{H})$ ratio of the patients with MS were significantly higher than those of the non-MS patients. In Table 2, MS and non-MS obese patients are compared according to their metabolic characteristics, anthropometric measurements and risk factors for MS.

The proportion of patients who had high triglyceride and total cholesterol levels were $82 \%$ and $18 \%$ in the MS group, while these rates were $31 \%$ and $15 \%$ in the non-MS group. There was a statistically significant difference between the two groups for triglyceride levels $(p<0.05)$, but not for total cholesterol ( $p>0.05$ ).

Impaired fasting plasma glucose was detected in 74 out of 240 patients who had MS vs. 17 of 374 non-MS obese patients $(p>0.05)$. Twelve patients had impaired glucose tolerance and 9 of these (75\%) had MS.

In 345 patients (56\%) who were defined as severely obese, BMI-SDS was above 2.5. The mean age of the severely obese patients was comparable to that of the subjects who were not severely obese $(11.2 \pm 2.5 \mathrm{vs}$. $11.4 \pm 2.5$ years, $p>0.05)$. MS was detected in $24 \%$ $(n=65 / 269)$ and $51 \%(n=175 / 345)$ of obese and severely obese patients, respectively $(p<0.05)$ (Figure $1 A$ ).

The numbers of family members who had cardiovascular disease, type 2 diabetes, obesity or hypertension were significantly higher in patients with $\mathrm{MS}(\mathrm{p}<0.05)$ (Figure 1B). MS was detected in $34 \%$ ( $n=89 / 259)$ of children who were exclusively breastfed in the first 6 months of life, while this rate was $52 \%(n=111 / 212)$ in children who were never breastfed $(p<0.05)$ (Figure $1 C)$. There was no significant difference between the birth weights of MS and non-MS patients (Table 2).

When the patients were divided into age groups as 7-11 years $(n=344)$ and $12-18$ years $(n=270)$, the prevalence of MS was found to be significantly higher in the second group (114/344 vs. 126/270, $p=0.00)$. Thirty percent $(n=90 / 296)$ of the prepubertal patients were diagnosed with MS vs. $47 \%$ ( $n=150 / 318)$ of the pubertal patients $(p<0.05)$ who were above 7 years old (Figure 1D).

Fasting plasma glucose, triglycerides, HDL-cholesterol, LDL-cholesterol, HbA1c, fasting insulin, and HOMA-IR index of the pubertal and non-pubertal cases are shown in Table 3. 


\section{Discussion}

MS is a cluster of risk factors which is becoming more prevalent concurrent with obesity. Although the prevalence figures differ by diagnostic criteria, the overall prevalence is estimated to be $3-4 \%$ (21). According to Cizmecioglu et al (10), 38.8\% of obese children in Turkey were diagnosed as having MS based on the WHO criteria, whereas the prevalence declined to $24 \%$ when the International Cholesterol Education Panel (NCEP) criteria were used. Miranda et al (22) reported from USA that the MS prevalence was $22 \%$ by NCEP criteria, while Isomaa et al (23) found this prevalence to be $42 \%$ based on the WHO criteria. In the present study, using the modified WHO criteria, the prevalence of MS was 39\% in 614 obese patients between 7 and 18 years of age. When these same patients were reevaluated with the modified Cook criteria, the MS prevalence decreased to $34 \%$. In addition, we found that $31 \%$ of the children aged $10-16$ years met the criteria for MS based on the pediatric MS definition of the IDF consensus. The overall prevalence with IDF criteria was $33 \%$ and this prevalence was lower than that obtained by other criteria. These different results indicate the necessity to conduct more studies in this field and to revise the diagnostic criteria.

In relevance to our study, we attempted to present an overview of previous reports on the prevalence of MS in Turkey. Kelestemur et al (7) reported from Kayseri that the

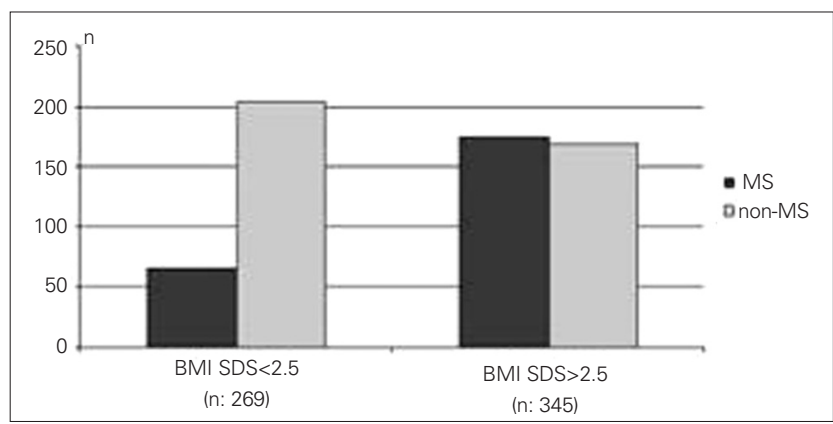

Figure 1A. MS prevalence was $24 \%$ and $51 \%$ in obese patients who have BMI-SDS $<2.5$ and BMI-SDS $>2.5$, respectively $(p<0.5)$

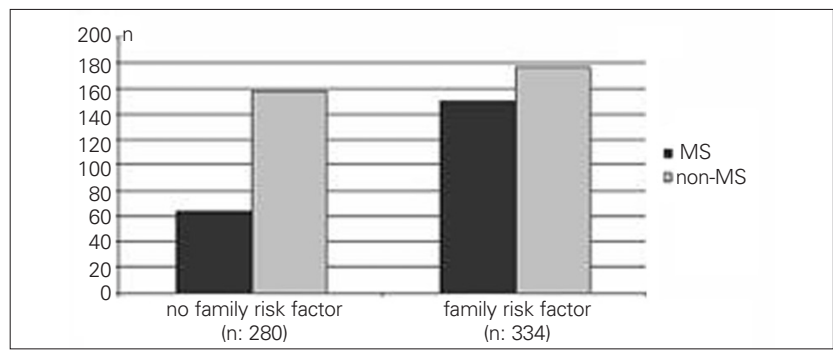

Figure 1B. MS prevalence was $22 \%$ and $52 \%$ in the patients who do not have and have family risk factors, respectively $(p<0.5)$ prevalence of MS in obese children was $20 \%$. In a study conducted in Ankara city, 4.9\% of the 1385 children between 10 and 17 years were obese, and the prevalence of MS in this obese population was estimated to be $21 \%$ (8). Atabek et al (9) identified the MS in $27.2 \%$ of obese children and adolescents in Konya city. In our study, the prevalence of MS according to the WHO criteria was similar to that reported by Cizmecioglu et al (11) (39\% vs. $38.8 \%)$, but higher as compared to the results of the previous studies cited above. This finding can be interpreted as a consequence of the gradually increasing prevalence of MS in children or indicates specific genetic or environmental characteristics of the population in different regions of Turkey. Climate, culture and dietary behaviors are known to vary significantly among the different regions of the country. Meat products and high-fat-containing meals are extensively consumed in some regions, while vegetables and vegetable oil constitute an important food item in other regions. Cold and long winters shorten the duration of outdoor games and enforce the children to a sedentary lifestyle. We consider that these factors affect the MS prevalence as well as the severity and prevalence of obesity in the different regions.

In this study, the prevalence of MS was significantly higher in the group which was between 12 and 18 years of age and in the pubertal group. Atabek et al (9) also found that $20 \%$ of obese children and $37.6 \%$ of adolescents have evidence of MS; however, their patients were not evaluated for pubertal status. There are many reports on the risk

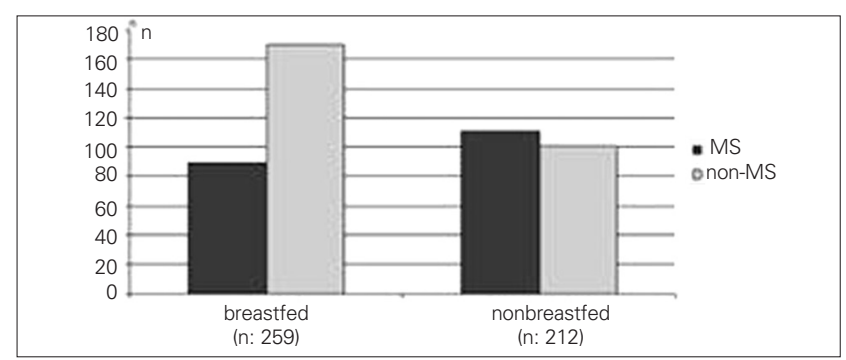

Figure 1C. MS prevalence was $34 \%$ and $52 \%$ in the patients who were exclusively or never breastfed, respectively $(p<0.5)$

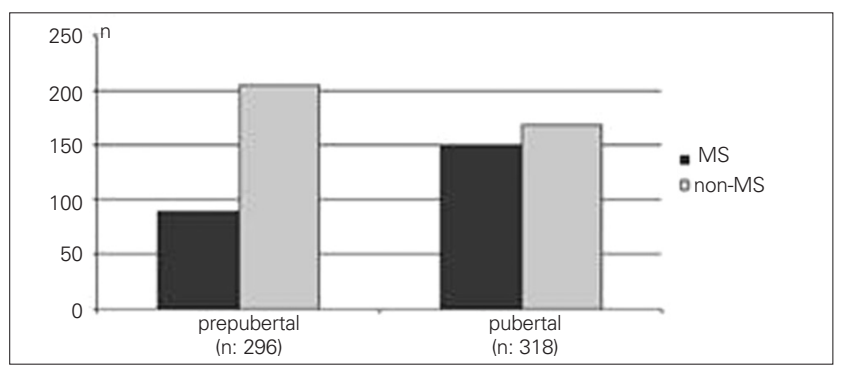

Figure 1D. MS prevalance was $30 \%$ and $47 \%$ in prepubertal and pubertal patients, respectively $(p<0.5)$ 
factors for MS and, particularly, on insulin resistance, BMI and puberty. It has been shown that when the adjusted insulin resistance according to ethnic origin and the degree of obesity increase, the prevalence of MS also increases (23). A prospective study investigating the cardiovascular risk factors in Finn youth has shown that MS develops in those with high initial insulin levels (24). On the other hand, according to the data of the Bogalusa Heart Study, high $\mathrm{BMI}$, independently from insulin resistance, increases the risk of MS (25). Costa et al (26) observed an association between BMI percentile and a cluster of cardiovascular risk factors, such as increased blood pressure, low HDLcholesterol, increased triglyceride levels, increased insulin levels, as well as insulin resistance. Pilia et al (27) studied the effect of puberty on insulin resistance and found that the increase in HOMA-IR in obese children at puberty is greater than that in normal-weight children. In this study, we observed significantly higher MS rates in patients in the pubertal group who had high triglyceride, low HDLcholesterol and high fasting insulin levels as well as high

Table 1. Clinical characteristics and laboratory parameters of the study population (mean $\pm S D$ values)

\begin{tabular}{|c|c|c|c|c|}
\hline & $\begin{array}{l}\text { Total group } \\
\qquad n=614\end{array}$ & $\begin{array}{l}\text { Males } \\
\mathrm{n}=\mathbf{3 0 7}\end{array}$ & $\begin{array}{c}\text { Females } \\
n=307\end{array}$ & $\mathbf{p}$ \\
\hline Age (years) & $11.3 \pm 2.5$ & $11.3 \pm 2.37$ & $11.29 \pm 2.64$ & 0.78 \\
\hline BMI-SDS & $2.57 \pm 0.59$ & $2.71 \pm 0.55$ & $2.43 \pm 0.59$ & 0.000 \\
\hline Birth weight (g) & $3383 \pm 709.3$ & $3435 \pm 755.3$ & $3332.3 \pm 657.5$ & 0.09 \\
\hline Breastfed (n) & 260 & 127 & 133 & 0.81 \\
\hline $\begin{array}{l}\text { Fasting glucose } \\
(\mathrm{mg} / \mathrm{dL})\end{array}$ & $90.9 \pm 13.5$ & $91.4 \pm 8.4$ & $90.4 \pm 17.1$ & 0.33 \\
\hline $\begin{array}{l}\text { Fasting insulin } \\
(\mathrm{mlU} / \mathrm{mL})\end{array}$ & $17.6 \pm 10.6$ & $16.8 \pm 9.68$ & $18.6 \pm 11.5$ & 0.64 \\
\hline $\begin{array}{l}\text { HDL-cholesterol } \\
\text { (mg/dL) }\end{array}$ & $44.6 \pm 10.69$ & $45 \pm 11.2$ & $44.2 \pm 10.1$ & 0.37 \\
\hline $\begin{array}{l}\text { LDL-cholesterol } \\
\text { (mg/dL) }\end{array}$ & $96.5 \pm 29.2$ & $98.2 \pm 30.3$ & $94.8 \pm 27.9$ & 0.19 \\
\hline $\begin{array}{l}\text { Triglycerides } \\
\text { (mg/dL) }\end{array}$ & $130.78 \pm 69.3$ & $130.7 \pm 71.2$ & $130.7 \pm 67.6$ & 0.99 \\
\hline $\mathrm{HbA1c}(\%)$ & $5 \pm 0.75$ & $5.15 \pm 0.68$ & $4.95 \pm 0.82$ & 0.006 \\
\hline HOMA-IR & $3.39 \pm 2.07$ & $3.18 \pm 1.77$ & $3.63 \pm 2.35$ & 0.016 \\
\hline Hypertension(n) & 232 & 128 & 104 & 0.42 \\
\hline Diagnosed MS* & 240 & 130 & 110 & 0.1 \\
\hline
\end{tabular}

HOMA-IR index and similar BMI-SDS values with prepubertal patients. Although MS patients have significantly higher BMI-SDS than non-MS patients, puberty is suggested to be one of the major predisposing factors of MS, irrespective of BMI.

Osei et al (28) demonstrated that within normal HbA1c limits, there were several anthropometric and metabolic differences among high-risk African-Americans for type 2 diabetes, belonging to the lower and upper $\mathrm{HbA} 1 \mathrm{c}$ tertiles. Although all $\mathrm{HbA} 1 \mathrm{c}$ levels were in the normal reference range, males had significantly higher $\mathrm{HbA} 1 \mathrm{c}$ levels than females in our study. This can be associated with the significantly higher BMI-SDS of the males. Even though the difference is not statistically significant, boys are more prone to be diagnosed with MS, which probably is the result of their higher BMI-SDS and HbA1c levels. However, HOMA-IR values in the females were higher than in males although their $\mathrm{BMI}$ and $\mathrm{HbA} 1 \mathrm{c}$ levels were lower. It is difficult to interpret these findings and to state that they result from the slightly higher insulin levels of females, a finding which was not statistically significant.

Sen et al (29) reported that MS was diagnosed in 38.7\% and $49.7 \%$ of obese (BMI-SDS: $2-2.5$ ) and severely obese

Table 2. Comparison of risk factors, metabolic characteristics and anthropometric measurements in $\mathrm{MS}^{*}$ and non-MS obese patients (mean \pm SD values and percentages)

\begin{tabular}{lccc}
\hline & $\begin{array}{c}\text { MS } \\
\mathbf{n}=\mathbf{2 4 0}\end{array}$ & $\begin{array}{c}\text { non-MS } \\
\mathbf{n}=\mathbf{3 7 4}\end{array}$ & $\mathbf{P}$ \\
\hline Age (years) & $11.8 \pm 2.32$ & $11 \pm 2.57$ & $\mathbf{0 . 0 0}$ \\
BMI SDS & $2.85 \pm 0.55$ & $2.39 \pm 0.54$ & $\mathbf{0 . 0 0}$ \\
Weight for height & $160.2 \pm 20.7$ & $142.6 \pm 13.5$ & $\mathbf{0 . 0 0}$ \\
Birth weight (g) & $3419.1 \pm 630.1$ & $3360.7 \pm 756.5$ & 0.35 \\
Fasting glucose (mg/dL) & $93.4 \pm 19.1$ & $89.2 \pm 7.4$ & 0.00 \\
HDL-cholesterol (mg/dL) & $38.4 \pm 7.6$ & $49.4 \pm 10.2$ & 0.00 \\
LDL-cholesterol (mg/dL) & $96.7 \pm 32$ & $96.4 \pm 27.3$ & 0.93 \\
Triglycerides (mg/dL) & $171.7 \pm 69.7$ & $103 \pm 53.8$ & 0.00 \\
HOMA-IR & $3.93 \pm 2.28$ & $3.03 \pm 1.8$ & 0.00 \\
HbA1c (\%) & $5.2 \pm 0.79$ & $4.96 \pm 0.72$ & 0.00 \\
Breastfed (n) & $89(37 \%)$ & $170(45 \%)$ & 0.00 \\
Pubertal (n) & $150(63 \%)$ & $168(45 \%)$ & 0.00 \\
Family history for diabetes & $176(73 \%)$ & $158(42 \%)$ & 0.00 \\
(n, \%) & & & \\
\hline
\end{tabular}

${ }^{*}$ According to the WHO criteria; MS: metabolic syndrome HOMA-IR: homeostasis model assessment for insulin resistance BMI-SDS: body mass index-standard deviation score 
adolescents (BMI-SDS>2.5), respectively. The prevalence of $\mathrm{MS}$ was determined as $28.7 \%$ in obese adolescents (BMI percentile $>95^{\text {th }}$ percentile) in another study, while it was $6.8 \%$ in overweight adolescents (BMI: 85-95th percentile) (12). Similarly, MS was detected with a prevalence of $24 \%$ and $52 \%$ in our obese and severely obese patients. These findings indicate a linear correlation between MS and severity of obesity.

MS risk is reported to be higher in children of families who have diabetes, heart disease, hypertension and disturbance of lipid metabolism $(30,31)$. We also found that the prevalence of MS is significantly higher in the children who have a family member with diabetes, hypertension, coronary artery disease or hyperlipidemia (Figure 1B). This can be attributed to the effect of genetic factors, but also may indicate similar environmental conditions, dietary habits, socioeconomic status and sedentary lifestyle.

Breast milk is found to be protective against some components of MS (32). It has been reported that the prevalence of obesity increases two-fold in children who were not breastfed as compared to breastfed children, with a concurrent increase in MS prevalence (33). However, Kelishadi et al (34) stated that breast milk has no protective effect against MS, but did not give any data on MS prevalence in non-breastfed children. In our study, the MS prevalence was significantly higher in the non-breastfed group. This result supports the idea that breast milk has a protective effect against obesity and, indirectly, against MS.

Some studies demonstrate that children who have low and high birth weight or a high weight gain in the early postnatal period are at higher risk of developing obesity and

\begin{tabular}{|c|c|c|c|}
\hline & $\begin{array}{l}\text { Prepubertal } \\
n=296\end{array}$ & $\begin{array}{c}\text { Pubertal } \\
\mathrm{n}=318\end{array}$ & $\mathbf{P}$ \\
\hline BMI-SDS & $2.59 \pm 0.6$ & $2.55 \pm 0.58$ & 0.43 \\
\hline Fasting glucose (mg/dL) & $90.9 \pm 17.2$ & $90.9 \pm 8.9$ & 0.94 \\
\hline Fasting insulin (mIU/mL) & $14.4 \pm 9.5$ & $20.5 \pm 10.7$ & 0.00 \\
\hline Triglycerides (mg/dL) & $121.2 \pm 66.9$ & $139.6 \pm 70.5$ & 0.00 \\
\hline HDL-cholesterol (mg/dL) & $45.8 \pm 11.1$ & $43.4 \pm 10.1$ & 0.01 \\
\hline LDL-cholesterol (mg/dL) & $98 \pm 29.6$ & $95.1 \pm 28.8$ & 0.27 \\
\hline $\mathrm{HbA1c}(\%)$ & $4.9 \pm 0.7$ & $5.1 \pm 0.78$ & 0.07 \\
\hline HOMA-IR & $2.8 \pm 1.9$ & $3.9 \pm 2$ & 0.00 \\
\hline Diagnosed MS (n, \%) & $90(30 \%)$ & $150(47 \%)$ & 0.00 \\
\hline
\end{tabular}

MS in older ages, while other studies found that neither gestation week nor birth weight is associated with MS $(35,36,37)$. Our results showed no significant correlation between MS and birth weight and supported the reports stating that birth weight is not being related to MS. However, further studies, particularly comparing children with high or low birth weights, are required to get more conclusive results on the relationships between birth weight and MS.

In conclusion, in parallel to the obesity epidemic, the prevalence of the MS in children and adolescents shows an alarming increase, becoming a growing problem in childhood. Severe obesity, age, pubertal status, presence of family history of cardiovascular disease, type 2 diabetes, obesity or hypertension and not being breastfed during infancy appear to be important risk factors associated with MS in childhood. Further studies are needed to revise the diagnostic criteria in childhood and to reach a consensus on the diagnosis of MS.

\section{References}

1. Strock GA, Cottrell ER, Abang AE, Buschbacher RM, Hannon TS. Childhood obesity: a simple equation with complex variables. J Long Term Eff Med Implants 2005; 15:15-32.

2. Cinaz P, Bideci A. Obesity. In Bideci A, Gunoz G, Ocal N, Yordam $S$ (eds). Pediatric Endocrinology, 1st Ed, Turkish Pediatric Endocrinology and Auxology Society Publishments. Ankara: Kalkan Press 2003;487-505.

3. Prevention and management of the global epidemic of obesity. Report of the WHO Consultation on Obesity. Geneva 1997.

4. Vainio $H$, Bianchini F. IARC Handbooks of cancer prevention. Volume 6: Weight control and physical activity. Lyon, France: IARC Press, 2002.

5. Wild SH, Byrne CD. The global burden of the metabolic syndrome and its consequences for diabetes and cardiovascular disease. In: Metabolic Syndrome. Chichester, England: John Wiley \& Sons Ltd; 2005:1-43.

6. Chen W, Bao W, Begum S, Elkasabany A, Srinivasan SR, Berenson GS. Age-related patterns of the clustering of cardiovascular risk variables of syndrome $X$ from childhood to young adulthood in a population made up of black and white subjects: the Bogalusa Heart Study. Diabetes 2000;49:1042-1048.

7. Kelestemur F, Cetin M, Pasaoglu H, Coksevim B, Cetinkaya F, Unluhizarci K, Unal S, Köker AH. The prevalence and identification of risk factors for T2DM and IGT in Kayseri, Central Anatolia, Turkey. Acta Diabetol 1999;36:85-91.

8. Agirbasli M, Cakir S, Ozme S, Ciliv G. Metabolic syndrome in Turkish children and adolescents. Metabolism 2006;55:1002-1006.

9. Atabek M, Pirgon O, Kurtoglu S. Prevalence of metabolic syndrome in Turkish children and adolescents. Diabetes Res Clin Pract 2006;72:315-321.

10. Cizmecioğlu FM, Hatun S, Kalaça S. Metabolic syndrome in obese Turkish children and adolescents: comparison of two diagnostic models. Turk J Pediatr 2008;50:359-365. 
11. Cizmecioglu FM, Etiler N, Hamzaoglu O, Hatun S. Prevalence of metabolic syndrome in schoolchildren and adolescents in Turkey: a population-based study. J Pediatr Endocrinol Metab 2009;22:703-714.

12. Cook S, Weitzman M, Auinger $P$, Nguyen M, Dietz WH. Prevalence of a metabolic syndrome phenotype in adolescents: findings from the third National Health and Nutrition Examination Survey, 1988-1994. Arch Pediatr Adolesc Med 2003;157:821-827

13. Zimmet $P$, Alberti KG, Kaufman $F$, Tajima $N$, Silink $M$, Arslanian S, Wong G, Bennett $P$, Shaw J, Caprio S; IDF Consensus Group. The metabolic syndrome in children and adolescents - an IDF consensus report. Pediatr Diabetes 2007;8:299-306.

14. http://www.cdc.gov/nccdphp/dnpa/bmi/childrens Access Date; 14.05.2010.

15. Tanner JM. Growth of Adolescents. Oxford, UK: Blackwell Scientific Publications; 1962

16. National High Blood Pressure Education Program Working Group on High Blood Pressure in Children and Adolescents. The forth report on te diagnosis, evaluation and treatment of high blood pressure in children and adolescents. Pediatrics 2004; 114:555-556.

17. Goran MI, Gower BA. Longitudinal study on pubertal insulin resistance. Diabetes 2001;50:2444-2450.

18. Levy JC, Matthews DR, Hermans MP. Correct Homeostasis Model Assessment (HOMA) Evaluation uses the computer program. Diabetes Care 1998;21:2191-2192.

19. Alberti KG, Zimmet PZ. Definition, diagnosis and classification of diabetes mellitus and its complications. Part 1: diagnosis and classification of diabetes mellitus provisional report of a WHO consultation. Diab Med 1998;15:539-553.

20. Hatipoglu N, Ozturk A, Mazicioglu MM, Kurtoglu S, Seyhan S, Lokoglu F. Waist circumference percentiles for 7-17 year old Turkish children and adolescents. Eur J Pediatr 2008;167:383-389.

21. Weiss R, Dziura J, Burgert TS, Tamborlane WV, Taksali SE, Yeckel CW, Allen K, Lopes M, Savoye M, Morrison J, Sherwin RS, Caprio S. Obesity and the metabolic syndrome in children and adolescents. N Engl J Med 2004;350:2362-2374.

22. Miranda PJ, De Fronzo RA, Califf RM, Guyton JR. Metabolic syndrome: Definition, pathophysiology, and mechanisms. Am Heart J 2005;149:33-45.

23. Isomaa $B$, Almgren $P$, Tuomi T, Forsén $B$, Lahti $K$, Nissén M, Taskinen MR, Groop L. Cardiovascular morbidity and mortality associated with metabolic syndrome. Diabetes Care 2001;24:683-689.

24. Raitakari OT, Porkka KV, Rönnemaa T, Knip M, Uhari M, Akerblom HK, Viikari JS. The role of insulin in clustering of serum lipids and blood pressure in children and adolescents. The Cardiovascular Risk in Young Finns Study. Diabetologia 1995;38:1042-1050.

25. Srinivasan SR, Myers L, Berenson GS. Predictability of childhood adiposity and insulin for developing insulin resistance syndrome in young adulthood: the Bogalusa Heart Study. Diabetes 2002;51:204-209.
26. Costa GB, Horta N, Resende ZF, Souza G, Barreto LM, Correia LH, Nascimento TA, Rios CB, Barreto-Filho JA, Lopes HF. Body mass index has a good correlation with proatherosclerotic profile in children and adolescents. Arq Bras Cardiol 2009;93:261-267.

27. Pilia S, Casini MR, Foschini ML, Minerba L, Musiu MC, Marras V, Civolani P, Loche S. The effect of puberty on insulin resistance in obese children. J Endocrinol Invest 2009;32:401-405.

28. Osei K, Rhinesmith S, Gaillard T, Schuster D. Is glycosylated hemoglobin $\mathrm{A} 1 \mathrm{C}$ a surrogate for metabolic syndrome in nondiabetic, first-degree relatives of African-American patients with type 2 diabetes? J Clin Endocrinol Metab 2003;88:4596-4601.

29. Sen Y, Aygun D, Yılmaz, Ayar A. Children and adolescents with obesity and the metabolic syndrome have high circulating cortisol levels. Neuro Endocrinol Lett 2008;29:141-145.

30. Wada K, Tamakoshi K, Yatsuya H, Otsuka R, Murata C, Zhang H, Takefuji S, Matsushita K, Sugiura K, Toyoshima H. Association between parental histories of hypertension, diabetes and dyslipidemia and the clustering of these disorders in offspring. Prev Med 2006;42:358-363.

31. Lee WY, Jung $\mathrm{CH}$, Park JS, Rhee EJ, Kim SW. Effects of smoking, alcohol, exercise, education, and family history on the metabolic syndrome as dened by the ATP III. Diabetes Res Clin Pract 2005;67:70-77.

32. Lawlor DA, Riddoch CJ, Page AS, Andersen LB, Wedderkopp N, Harro M, Stansbie D, Smith GD. Infant feeding and components of metabolic syndrome: findings from the European Youth Hearth Study. Ach Dis Child 2005;90:582-588

33. von Kries R, Koletzko B, Sauerwald T, von Mutius E. Does breast-feeding protect against childhood obesity? Adv Exp Med Biol 2000;478:29-39.

34. Kelishadi R, Gouya MM, Adeli K, Ardalan G, Gheiratmand R, Majdzadeh R, Mahmoud-Arabi MS, Delavari A, Riazi MM, Barekati H, Motaghian M, Shariatinejad K, Heshmat R; CASPIAN Study Group. Factors associated with the metabolic syndrome in a national sample of youths: CASPIAN Study. Nutr Metab Cardiovasc Dis 2008;18:461-70.

35. Willemsen RH, Leunissen RW, Stijnen T, Hokken-Koelega AC. Prematurity is not associated with reduced insulin sensitivity in adulthood. J Clin Endocrinol Metab 2009;94:1695-1700.

36. Huang RC, Burke V, Newnham JP, Stanley FJ, Kendall GE, Landau LI, Oddy WH, Blake KV, Palmer LJ, Beilin LJ. Perinatal and childhood origins of cardiovascular disease. Int J Obes (Lond) 2007;31:236-244.

37. Tzoulaki I, Sovio U, Pillas D, Hartikainen AL, Pouta A, Laitinen J, Tammelin TH, Jarvelin MR, Elliott P. Relation of immediate postnatal growth with obesity and related metabolic risk factors in adulthood: the northern Finland birth cohort 1966 study. Am J Epidemiol 2010;171:989-998. 